\title{
Physiological Effects of N95 FFP and Personal Protective Equipment in Healthcare Workers in COVID ICU: A Prospective Cohort Study
}

\author{
Simant Kumar Jha
}

Keywords: COVID-19, Doffing, Donning, Healthcare workers, N95 mask with facepiece respirator, Perfusion index, Personal protective equipment, Physiological impact, RPE.

Indian Journal of Critical Care Medicine (2020): 10.5005/jp-journals-10071-23690

Personal protective equipment (PPE) including facemask continues to give protection to healthcare workers (HCWs) against deadly contagious coronavirus disease (COVID) and non-COVID droplet infections. In 2003, World Health Organization (WHO) and in 2004, US Centre for Disease Control (CDC) made guidelines for PPE, facemask with $95 \%$ filtration coefficient or above for $\mathrm{HCW}$ s exposed to SARS patients. ${ }^{1}$ In 1987 , Nielsen et al. found that the thermal sensation of the whole body was significantly influenced by the facemask air temperature. ${ }^{2}$

In 1997, it was reported by Meyer et al. that the acceptable duration of respiratory device use was 1 hour in air temperature of $18^{\circ} \mathrm{C}$ and it was found that with a rise in air temperature comfort sensation was reduced. ${ }^{3,4}$ In another study by the Roberge group (2010) on healthy HCWs reported that there was no significant difference in moisture retention between facepiece respirator (FFR) and control group in the physiological variable, exertion score, and comfort score. Finally, a conclusion made by Roberge, Coca, Jon Williams, Jeffrey, B Powell, and Andrew J Palmiero who assessed the physiological impact of the N95 FFR on HCWs in 2010 was that both FFR (with/without valve) had only mild physiological impact in clinically realistic low work conditions for 1 hour. Also, the mixed inhalation/exhalation $\mathrm{O}_{2}$ and $\mathrm{CO}_{2}$ levels in the FFR V1 did not meet the occupational safety and administration standards for workplace $\mathrm{O}_{2}$ and $\mathrm{CO}_{2}$ concentration.

The health and safety of HCWs are of utmost importance in this COVID pandemic; however, the baseline data regarding the physiological effects occurring in them after prolonged use of PPE remains unexplored. ${ }^{5}$

In the current issue of IJCCM, great work has been done by Choudhary et al. The author enrolled $75 \mathrm{HCWs}$ to explore the physiological effects of PPE and facemask with FFR and divided into two groups. A modified CR10 scale by Foster et al. was chosen for a rating of perceived exertion at the beginning of the morning shift through a pulse oximeter. Dyspnea was assessed through the Modified Borg Scale. ${ }^{6}$ Parameters such as were heart rate, $\mathrm{SpO}_{2}$, perfusion index, rating of perceived exertion, and dyspnea at baseline before wearing FFR, at the end of 4 hours of light work, before donning PPE, and postdoffing were recorded SPSS statistical software version 24 was used for statistical analysis. Results showed significant tachycardia postdoffing when compared with baseline heart rate at 4 hours N95 FFR application and predonning.

Perfusion index was decreased following doffing when compared with baseline perfusion index. Similar behavior was shown as far as $\mathrm{SpO}_{2}$ was concerned. A decrease in $\mathrm{SpO}_{2}$ was noted
Department of Critical Care, Pushpawati Singhania Hospital and Research Institute, New Delhi, India

Corresponding Author: Simant Kumar Jha, Department of Critical Care, Pushpawati Singhania Hospital and Research Institute, New Delhi, India, Phone: +918800149020, e-mail: drsimant2007@gmail. com

How to cite this article: Jha SK. Physiological Effects of N95 FFP and Personal Protective Equipment in Healthcare Workers in COVID ICU: A Prospective Cohort Study. Indian J Crit Care Med 2020;24(12): 1156-1157.

Source of support: Nil

Conflict of interest: None

in the postdoffing period compared with baseline saturation, 4 hours post N95, and predonning. RPE score was markedly increased when it was compared with PPE off (doffing) vs PPE on (donning). Even 4 hours of N95 RPE score was high compared with baseline. Modified Borg Scale of dyspnea showed a significant difference when postdonning and doffing were compared with baseline. ${ }^{6,7}$

As far as adverse effects were concerned fogging was seen in all 75 participants followed by headache (90\%), tiredness (70.65\%), difficulty in breathing (60\%), mask soakage (24\%), PPE breach (4\%), palpitation (2.67\%) followed by bronchospasm (1.33\%). They studied the changes in the physiological parameters (an increased $\mathrm{HR}$, decreased $\mathrm{SpO}_{2}$, and $\left.\mathrm{PI}\right){ }^{7,8}$ These changes combined with the anxiety and fears related to this pandemic and direct exposure to increased viral loads makes them more vulnerable to infection in PPE or decreased immunity.

These changes point toward the need for institutional policies for better working conditions for the HCWs, shorter working shifts, or appropriate breaks during the shifts to maintain hydration and rest. Also, research on better quality PPE is required as these HCWs are frontline warriors on whom the medical care rests in this pandemic. All physiological changes related to wearing N95 facemask like tachycardia, hypertension, increased aortic and left ventricular pressure, increased pulmonary artery pressure, decreased $\mathrm{SpO}_{2}$, headache, fatigue, dizziness, and drowsiness are related to hypoxia and hypercarbia., ${ }^{5,8,9}$ The study by Chaudhary et al. did not measure the partial pressure of $\mathrm{O}_{2}, \mathrm{CO}_{2}$, and lactate level that might have given more conclusive evidence for physiological changes, as major limitations. Another limitation was its small sample size. Further studies are needed in the future measuring $\mathrm{PCO}_{2}, \mathrm{PO}_{2}$, and lactates in participants for better interpretation.

(c) The Author(s). 2020 Open Access This article is distributed under the terms of the Creative Commons Attribution 4.0 International License (https://creativecommons. org/licenses/by-nc/4.0/), which permits unrestricted use, distribution, and non-commercial reproduction in any medium, provided you give appropriate credit to the original author(s) and the source, provide a link to the Creative Commons license, and indicate if changes were made. The Creative Commons Public Domain Dedication waiver (http://creativecommons.org/publicdomain/zero/1.0/) applies to the data made available in this article, unless otherwise stated. 


\section{References}

1. Seto WH, Tsang D, Yung RW, Ching TY, Ng TK, Ho M, et al. Advisors of expert SARS group of hospital authority. Effectiveness of precautions against droplets and contact in prevention of nosocomial transmission of severe acute respiratory syndrome (SARS). Lancet 2003;361(9368):1519-1520. DOI: 10.1016/S0140-6736(03)13168-6.

2. Nielsen R, Berglund LG, Gwosdow AR, Dubois AB. Thermal sensation of the body as influenced by the thermal microclimate in a face mask. 1987;30(12):1689-1703.

3. Meyer JP, Héry M, Herrault J, Hubert G, François D, Hecht G, et al. Field study of subjective assessment of negative pressure half-masks. Influence of the work conditions on comfort and efficiency. Appl Ergon 1997;28(5-6):331-338. DOI: 10.1016/S0003-6870(97)00007-0.

4. Li Y, Tokura H, Guo YP, Wong AS, Wong T, Chung J, et al. Effects of wearing $\mathrm{N} 95$ and surgical facemasks on heart rate, thermal stress and subjective sensations. Int Arch Occup Environ Health 2005;78(6):501509. DOI: 10.1007/s00420-004-0584-4.
5. Roberge RJ, Coca A, Williams WJ, Powell JB, Palmiero AJ. Physiological impact of the N95 filtering facepiece respirator on healthcare workers. Respir Care 2010;55(5):569-577.

6. Wilson RC, Jones PW. A comparison of the visual analogue scale and modified Borg scale for the measurement of dyspnoea during exercise. Clin Sci 1989;76(3):277-282. DOI: 10.1042/cs0760277.

7. Kaye J, Buchanan F, Kendrick A, Johnson P, Lowry C, Bailey J, et al. Acute carbon dioxide exposure in healthy adults: evaluation of a novel means of investigating a stress response. J Neuroendocrinol 2004;16(3):256-264. DOI: 10.1111/j.0953-8194.2004.01158.x.

8. Laferty EA, McKay RT. Physiologic effects and measurement of carbon dioxide and oxygen levels during qualitative respirator fit testing. $J$ Chem Health Safe 2006;13(5):22-28. DOI: 10.1016/j.jchas.2005.11.015.

9. Hsu W-H, Liu W-C. Assessment of physiological loads and subjective discomforts for wearing N95 facemask. (Abstract). Healthcare Systems Ergonomics and Patient Safety International Conference, Strasbourg, FR. Jun 25-27, 2008, [Accessed 15 Apr 2009]. 